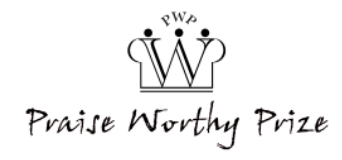

\title{
Launch Environment Ground Test Evaluation with Multi-axis Vibration and Shock for Pouch Solid-State-Ceramic Battery Advanced Energy Storage
}

\author{
Lakhdar Limam $^{1}$, Ken Hatanaka ${ }^{1}$, Jesus Gonzalez-Llorente ${ }^{1,2}$, \\ Masayuki Miyazaki ${ }^{1}$, Takeya Chikashi ${ }^{1}$, Kei-Ichi Okuyama ${ }^{1,3}$
}

\begin{abstract}
Satellites must endure the hostile environement during their launching to space via rocket; therefore, they should be exposed to the real launch conditions for ground testing, including all subsystems and components which should be carefully tested. Several solid-stateceramic batteries have been selected to be evaluated under the launch environment after been evaluated under the space environment, which has shown so far good results. This paper focuses on the physical degradation and the electrical performances of the batteries based on the discharge capacity, the open-circuit voltage, and charge/discharge modes. Batteries have been exposed to shock, then tested under vibration within different frequencies' levels with sinewave, sine burst, and random. Before and after the test, the physical properties of all batteries have been checked, several cycles of discharge and charge have been performed to check their performances and survivability after the evaluation test. With $95 \%$ of capacity, batteries could demonstrate their ability to withstand the launch conditions successfully, they could be able to operate during several cycles after the test, so far, showing no degradation on their performances within the limits. Also, the paper is providing the main requirements and criteria for batteries' launch ground testing for the small satellite project. Copyright (C) 2020 The Authors.

Published by Praise Worthy Prize S.r.l. This article is open access published under the CC BY-NC-ND license (http://creativecommons.org/licenses/by-nc-nd/3.0/).
\end{abstract}

Keywords: Solid-State Battery, Small satellite, Launch Environment, Low Earth Orbit, Vibration \& Shock Test

\section{Introduction}

Even with the long history and large application of the Lithium-Ion batteries, since they have been the most used in large mobile applications: form ground such as cellphones and electrical vehicles, to space with spacecraft and space suits, they have been categorized as hazardous batteries [1], especially after a bad manipulation or working under extreme conditions [2].

The manufacturers and users have been required to cover several test conditions following different requirements such as vibration and shock to verify their ability to work safely at the nominal level and good performances. According to the mechanical design of the Lithium-Ion batteries, the vibration and shock conditions can have a significant effect on the batteries' performances. Concerning these effects, internal shorts may occur which can lead to venting the electrolyte with the possibility of firing and thermal runaway. It may lead to breaking the cells and leakage in the case of liquid or jelly batteries [3]. At the work was done by Lijun Zhang, it has been identified that the vibration may lead to a significant increase in discharge resistance [4].

Eventually, the vibration and shock test for batteries became necessary due to the effect which could apport on the performances, like for the study done by Martin J. Brand, in which the effect of vibration and shock have been evaluated on two different battery structure: Cylindrical and Pouch, which the results have shown no degradation on the pouch batteries [5]. Or the work was done by James Michael Hooper on a multi-axis vibration test on the Li-Ion cylindric cells, for their electrical and physical evaluation [6], [7]. Then, the work was done by J-K Lee on the Pouch Lithium-Polymer battery in which the accelerated vibration and the charge-discharge cycling have been combined has shown good mechanical and electrical stability of the batteries [8]. However, Gunnar Kjell and Jenny Frodelius Lang have concluded with the comparison between different vibration test standard limits on the li-ion batteries and fatigue damage on the mechanical structure that the standards differ strongly and should be considered for the purpose which the battery will be used [9]. For the space applications, the primary objective is to ensure that the satellite and all components have passed the qualification test and free from workmanship defects. That why all kinds of energy storage including the batteries should be qualified for space used, otherwise, they should be evaluated and tested before launch to space. These are some examples 
of the qualification test done on the batteries for small satellites including the launch environment, in which KH. Park has presented the qualification test for the secured reliability of the Lithium-Ion batteries [10], moreover, the test was done by Saft and ESA for the qualification and life testing of the Saft Li-ion batteries [11]. Or the evaluation of variable cylindric cells by Jonghoon Kim, in which several batteries have been tested to evaluate their capacity and internal resistance [12], and another work for a battery certification for small satellite done by Zachary Cameron, for the Li-Ion cylindric cells test procedure [13]. Finally, the work was done by João P. Monteiro during the integration, and the verification approach of ISTSat-1 CubeSat is one of a good example for testing one kind of the solid-statepolymer battery for space use [14]. In this paper, for the first time, commercial solid-state-ceramic batteries have been tested under vibration and shock for the space application use. The same kind of batteries, in which have never been flown in space, have been previously evaluated under vacuum and thermal vacuum for the low earth orbit, which the results have been presented in different paper [15], the work has been done as part of the long evaluation process of the solid-state-ceramic batteries for the in-orbit demonstration mission onboard the future satellite. The feature of these kinds of batteries compared to other conventional batteries is having a solid ceramic electrolyte instead of liquid (LIB: Lithium-Ion battery) or gel (LPB: Lithium-Polymer Battery), which makes it very special for the safety issues with no risk for flammable liquid leakage. Compared to the other solidstate batteries, the solid ceramic electrolyte has a high elastic moduli makes it able to work at high temperatures [16], [17]. Since there are a few kinds of research and publications related to the vibration and the shock test for batteries for space use, this work is summarizing the main steps and procedure as a guideline for launch environment evaluation test which could be applied to not only solid-state-ceramic batteries but to all kind of energy storages and satellite's sub-systems.

The paper consists of five parts. Following the introduction in Section I, with the previous work have been discussing, Section II is about the description of the selected battery and the test preparation. Section III presents the inputs test condition required for launch environment, and the description in detail of the full test procedure and methodology. The reel test conditions applied on the batteries, the results and discussion are explained in Section IV. Finally, section V presents the conclusion and the future work plan.

\section{Solid-State-Battery Selection and Test Preparation Description}

During the launch environment test, a set of commercial solid-state-ceramic pouch batteries with two different capacities, the same kind of batteries that have been previously evaluated under the space environment, for vacuum and thermal vacuum [15], have been selected for the shock and the vibration ground test. The approach for evaluating the performance and the effect of the test conditions on batteries has been done following several discharges and charges cycles using a test board designed for this purpose [15]. The discharge cycles have been used for the discharge capacity ratio calculation, and the capacity before the test has been used as a reference capacity for comparison with the capacity after the test.

To support the batteries during the vibration and shock test, a tailor-made jig has been designed, with a natural frequency of $2981 \mathrm{~Hz}$. The performance of the jig has been checked with simulation for the three-axis and different modes using Solidworks software to confirm its ability to waistband the test conditions safely.

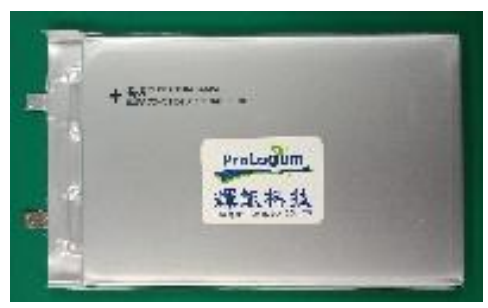

(a)

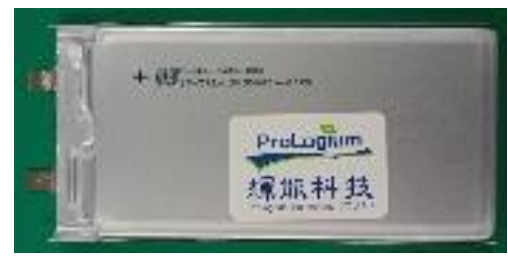

(b)

Figs. 1. Solid-state-ceramic battery ((a) LCB01, (b) LCB02) selected for evaluation test [15]

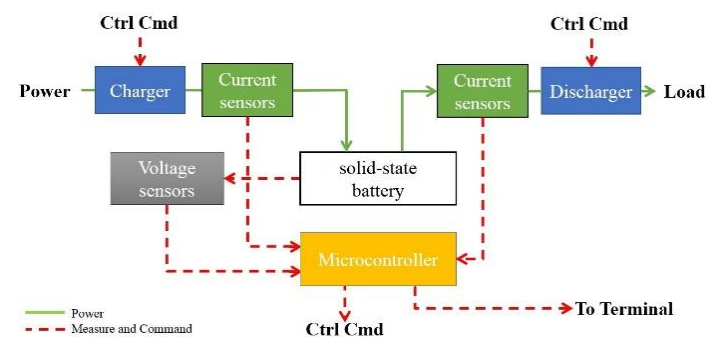

Fig. 2. Test board functional block diagram used for charge and discharge during the evolution test [15]

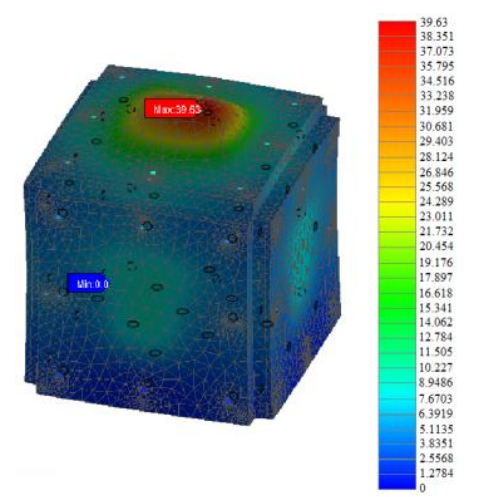

Fig. 3. Jig natural frequency and deformation simulation 


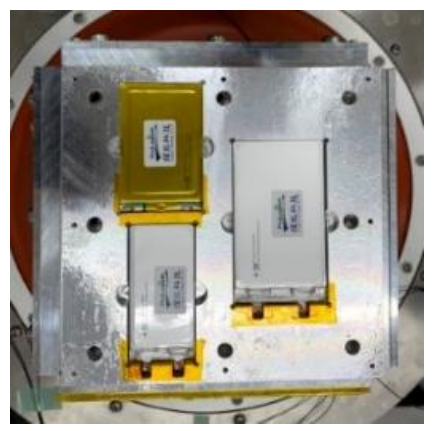

Fig. 4. Solid-state-ceramic batteries mounted on the jig before the vibration test

TABLE I

SOLID-STATE-CERAMIC BATTERIES SPECIFICATION [14]

\begin{tabular}{ccc}
\hline \hline Lithium Ceramic Battery & LCB01 & LCB02 \\
\hline Nominal Voltage $(\mathrm{V})$ & 3.75 & 3.75 \\
Nominal Capacity $(\mathrm{mAh})$ & 1950 & 1450 \\
Energy $(\mathrm{Wh})$ & 7.3125 & 5.4375 \\
Operation voltage $(\mathrm{V})$ & $4.35 \sim 2.75$ & $4.35 \sim 2.75$ \\
Size $(\mathrm{mm})$ & $4.5 \times 60 \times 105$ & $6.3 \times 42 \times 88$ \\
Weight $(\mathrm{g})$ & 59.5 & 45 \\
Operating temperature $\left({ }^{\circ} \mathrm{C}\right)$ & $-20 \sim 60$ & $-20 \sim 60$ \\
\hline \hline
\end{tabular}

Since the solid-state-ceramic batteries are planned to be launched on the same rocket as Ten-Koh satellite, the Japanese rocket H2A [18], [19], the same approach for the launch conditions previously adopted by Jesus Gonzalez for the solar modules integrated converters [20], as well as the Lithium-Ion battery pack for the TenKoh satellite and all its subsystems [21], [22], have been reproduced as the input's requirements for the launch environment ground test. Two different test facilities have been selected to satisfy the test conditions. Table II summarizes the specification for all the test equipment, first for the vibration machine which has the capability for testing under sine and random, and then the other machine used for the shock test.

\section{Launch Environment Evaluation Test's Conditions and Procedure}

The purpose of the launch environment evaluation test is to check the ability of the solid-state-ceramic batteries to withstand the conditions during launch and separation from the rocket. The hostile shock and vibration conditions are applied according to the defined $\mathrm{H} 2 \mathrm{~A}$ rocket requirements. During the launch environment test, a group of the six solid-state-ceramic batteries P1X, P1Y, and P1Z for LCB01, P2X, P2Y, and P3Z for LCB02 have been tested during two steps: once the group has been exposed to shock condition, and then it has been tested under several vibration environments.

TABLE II

List Of THE EQUIPMENT USED DURING THE EVALUATION TEST

\begin{tabular}{ccc}
\hline \hline Name & Type & Range \\
\hline Vibration machine & A30 (TBD-A30) & $5 \mathrm{~Hz}$ to $2600 \mathrm{~Hz}$ \\
Shock machine & CeNT & $4000 \mathrm{G}$ \\
Cubed jig & TCJ-B200-A30-A & DC $\sim 2000 \mathrm{~Hz}$ \\
SSB Jig & Jig for SSB (Original) & $2981 \mathrm{~Hz}$ \\
\hline \hline
\end{tabular}

The robustness of the solid-state-ceramic batteries has been evaluated carefully. Before and after each test, the solid-state batteries have been inspected with a visual check, measurement of physical property: weight, length, width, and thickness, then the electrical measurement of the open-circuit voltage and the discharge capacity, finally charged and discharged during several cycles.

\section{III.1. Shock Test}

For the high frequency from 100 to $5000 \mathrm{~Hz}$, the shock test is needed to simulate the conditions during the rocket stage, fairing, and satellite separation. The six solid-state-ceramic batteries have been distributed in three different groups and then exposed to a short shock duration with more than $1000 \mathrm{G}$. The accelerometers have not been attached to the test article directly but to the support jig, because the battery survival is the main concern for the test. Thus, only the input shock spectrum has to be measured.

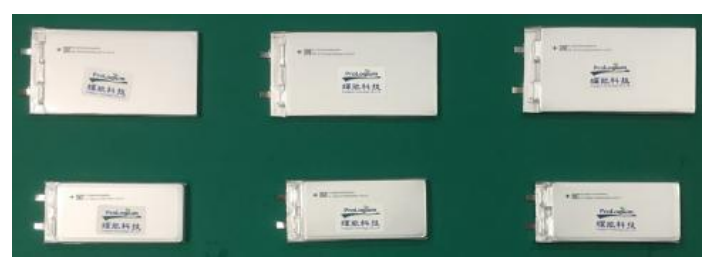

Fig. 5. Solid-state-ceramic batteries selected for the launch environment ground evaluation

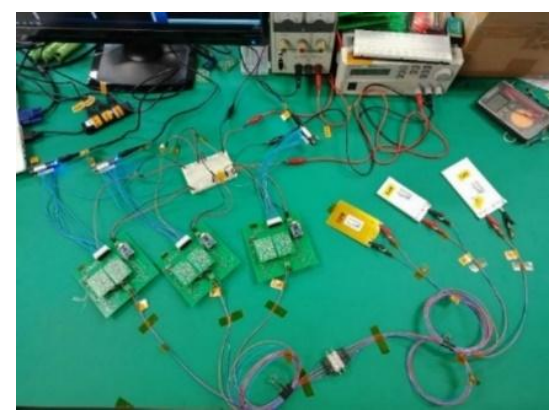

Fig. 6. Solid-state-ceramic battery charged and discharged before and after each test. Discharge condition: constant current (CC): DC: $0.5 \mathrm{C}$, EOD: $2.8 \mathrm{~V}$. Charge condition: constant-current constant-voltage (CC/CV): CC: 0.5C, CV: 4.35V, LCB01 EOC: 97.5mA, LCB02 EOC: $72.5 \mathrm{~mA}[15]$

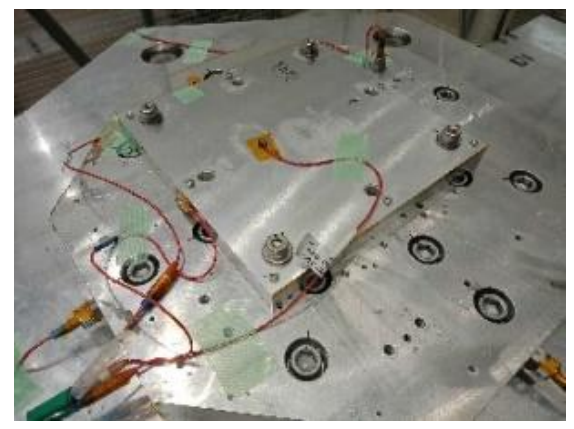

Fig. 7. The shock test's pickup sensors configuration for the solid-stateceramic batteries mounted on the shock machine 


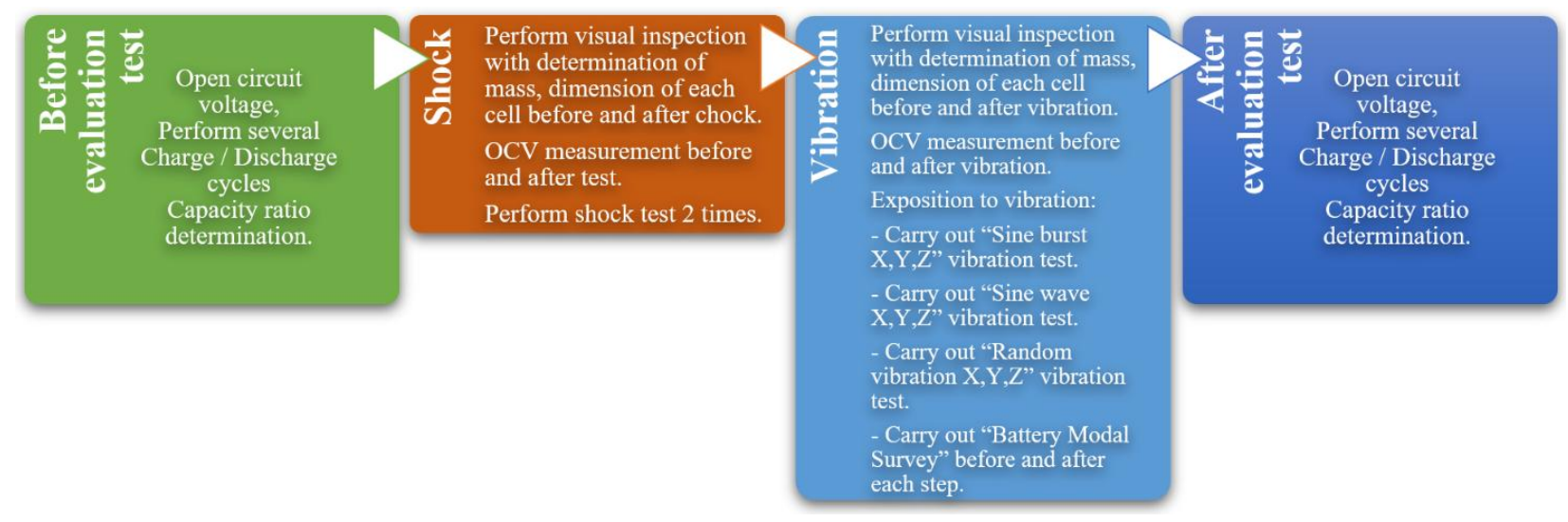

Fig. 8. Launch environment test flowchart summarized in fourth parts: before the test, shock, vibration, and after the test.

The quasi-static acceleration test is carried out by replacing it with a sine burst test

The inputs shock spectrums conditions for the shock evaluation test are the qualification level (QT) of the $\mathrm{H} 2 \mathrm{~A}$ rocket which is represented in Table III. Typically, the required shock level is between 1000 to $4000 \mathrm{G}$ within the frequency range from 100 to $5000 \mathrm{~Hz}$ [23].

\section{III.2. Vibration Test}

The purpose of the vibration test is to check the compliance of the solid-state-ceramic batteries with the vibration that may occur during the launch, they should be able to keep at least the same performances without degradation or malfunctions for the next operation in orbit. During the vibration test, the launch environment conditions defined as the qualification test level for batteries required by JAXA for the $\mathrm{H} 2 \mathrm{~A}$ rocket, have been reproduced as the input required for the test. The solid-state-ceramic batteries have been tested under low and high frequencies:

- Quasi-static or sine-burst: Demonstration against the static acceleration in the longitudinal and lateral direction. The maximum quasi-static acceleration is a combination of the static acceleration and the lowfrequency dynamic acceleration [18]. Typically, the number of cycles is 3 to 5 . A sine-burst is often selected reason for the difficulty to get the static acceleration in one direction. The test's frequency should be lower than the item's natural frequency;

- Sinusoidal: It is often standardized rather than quasistatic acceleration conditions with a low frequency (from 5 to $100 \mathrm{~Hz}$ ) within 2 minutes in the longitudinal and lateral direction;

- Random: For the high frequency (from 20 to 2000 $\mathrm{Hz}$ ), it is caused by the acoustic noise [18].

The solid-state-ceramic batteries have been divided into three jigs, each jig contained one battery from each sample, and it has been tested three times following three configurations. The following distribution allowed us to test the three axes for all batteries sequentially. During the first configuration, the solid-state-ceramic batteries have been mounted into the three jigs $(1,2$, and 3$)$ where the tested axes for batteries $(\mathrm{x}, \mathrm{y}$, and $\mathrm{z}$ ) have followed respectively the vibration machine axes $(\mathrm{X}, \mathrm{Y}, \mathrm{Z})$ in which the vibration will be applied ( $\mathrm{X}$ for jig $1, \mathrm{Y}$ for $\mathrm{jig}$ 2 , and then $Z$ for jig 3). Then after each test's sequence (sine burst, sinewave, and random), the three jigs are rotated, which the following tested axis for the battery should be respectively ( $\mathrm{Y}$ for jig1, $\mathrm{Z}$ for jig2, and $\mathrm{X}$ for jig3); finally, the last rotation. Figs. 9 and Table 7 summarize all the three configurations with the three rotations for each test's sequence.

TABLE III

INPUTS TEST CONDITION FOR THE SHOCK TEST [20]

\begin{tabular}{cccc}
\hline \multicolumn{3}{c}{ INPUTS TEST CONDITION FOR THE SHOCK TEST [20] } \\
Axis & $\begin{array}{c}\text { Frequency range } \\
(\mathrm{Hz})\end{array}$ & $\begin{array}{c}\text { Shock Response } \\
\text { Spectrum (SRS) }\end{array}$ & $\begin{array}{c}\text { Number of } \\
\text { tests }\end{array}$ \\
\hline $\mathrm{X}$ (longitude) & $100 \sim 2600$ & $+6 \mathrm{~dB} /$ octave & 2 times \\
Y and Z (lateral) & $2600 \sim 5000$ & $2000 \mathrm{G}$ & \\
\hline \hline
\end{tabular}

TABLE IV

SiNE BURST INPUTS TESTING PARAMETERS [20], [24]

\begin{tabular}{cccc}
\hline \hline Direction & Frequency $[\mathrm{Hz}]$ & Acceleration & Excitation time $[\mathrm{s}]$ \\
\hline \multirow{2}{*}{$\mathrm{X}$ axis } & & $58.8 \mathrm{~m} / \mathrm{s}_{0-\mathrm{p}}{ }^{2}$ & \\
& \multirow{2}{*}{20} & $7.5 \mathrm{G}_{0-\mathrm{p}}$ & \multirow{2}{*}{1} \\
$\mathrm{Y}, \mathrm{Z}$ axis & & $49 \mathrm{~m} / \mathrm{s}_{0-\mathrm{p}}{ }^{2}$ & \\
& & $6.25 \mathrm{G}_{0-\mathrm{p}}$ & \\
\hline \hline
\end{tabular}

TABLE V

SinUSOIDAL VibRATION INPUTS TESTING PARAMETERS [20], [24]

\begin{tabular}{cccc}
\hline \hline Direction & Frequency $[\mathrm{Hz}]$ & Level & Excitation time [oct/min] \\
\hline & $5-7.1$ & $0.02 \mathrm{~m}_{0-\mathrm{p}}$ & \\
$\mathrm{X}$ axis & $7.1-100$ & $30.7 \mathrm{~m} / \mathrm{s}_{0-\mathrm{p}}$ & \\
& $5-6.3$ & $3.13 \mathrm{G}_{0-\mathrm{p}}$ & 2 (UP and DOWN) \\
& $0.02 \mathrm{~m}_{0-\mathrm{p}}$ & \\
$\mathrm{Y}, \mathrm{Z}$ axis & $6.3-100$ & $24.5 \mathrm{~m} / \mathrm{s}_{0-\mathrm{p}}$ & \\
& & $2.5 \mathrm{G}_{0-\mathrm{p}}$ & \\
\hline \hline
\end{tabular}

TABLE VI

RANDOM VIBRATION INPUTS TESTING PARAMETERS [20], [24] \begin{tabular}{lll}
\hline Direction Frequency [Hz] & Level & Excitation time [s] RMS value \\
\hline
\end{tabular} \begin{tabular}{lcccc}
\hline \multirow{2}{*}{3 Axis } & $20-200$ & $+3 \mathrm{~dB} /$ oct & \multirow{2}{*}{120} & $11 \mathrm{Grms}$ \\
\hline \hline
\end{tabular}

TABLE VII

SOliD-STATE-CERAMIC BATTERIES Distribution For THE THREE CONFIGURATIONS DURING THE THREE TEST'S SEQUENCE: SiNE BURST, SINEWAVE AND RANDOM

\begin{tabular}{|c|c|c|c|c|c|c|}
\hline \multirow{2}{*}{$\begin{array}{c}\text { Configuration } \\
\# 1\end{array}$} & \multicolumn{2}{|c|}{ Jig 1} & \multicolumn{2}{|c|}{ Jig 2} & \multicolumn{2}{|c|}{ Jig 3} \\
\hline & P1x & $\mathrm{P} 2 \mathrm{x}$ & P1y & $\mathrm{P} 2 \mathrm{y}$ & $\mathrm{P} 1 \mathrm{z}$ & $\mathrm{P} 2 \mathrm{z}$ \\
\hline$\# 2$ & P1y & $\mathrm{P} 2 \mathrm{y}$ & $\mathrm{P} 1 \mathrm{z}$ & $\mathrm{P} 2 \mathrm{z}$ & $\mathrm{P} 1 \mathrm{x}$ & $\mathrm{P} 2 \mathrm{x}$ \\
\hline \#3 & $\mathrm{P} 1 \mathrm{z}$ & $\mathrm{P} 2 \mathrm{z}$ & $\mathrm{P} 1 \mathrm{x}$ & $\mathrm{P} 2 \mathrm{x}$ & P1y & $\mathrm{P} 2 \mathrm{y}$ \\
\hline
\end{tabular}




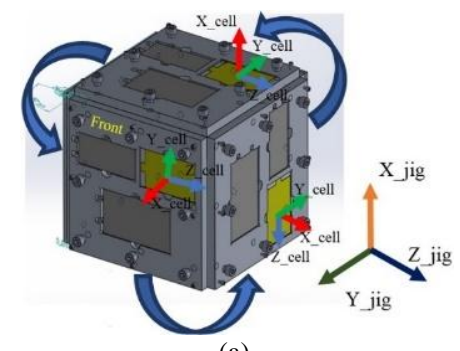

(a)

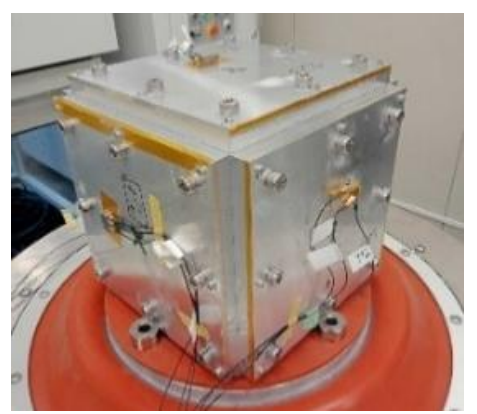

(b)

Figs. 9. Solid-state-ceramic batteries' configuration during the vibration test: (a) Solid-state-ceramic batteries' configuration inside the jig during the three axes rotations, (b) The pickup sensors' configuration for the three jigs

\section{III.2.1. Vibration Test Sequence}

The following test sequence should be carried out during all the three rotations for the vibration test:

1. Solid-state-ceramic batteries should be mounted according to the first configuration (Table VII);

2. Starting the first sequence for the $\mathrm{x}$-axis:

$\checkmark$ Performing X-axis Sine burst vibration;

$\checkmark$ Performing $x$-axis Sine wave vibration;

$\checkmark$ Performing $\mathrm{x}$-axis Random vibration.

3. Changing to the second configuration (Table VII), then the sequence at step 2 should be repeated for the y-axis;

4. Finally, repeating the sequence at step 2 for the last configuration for the z-axis.

\section{Test Result and Discussion}

Considering the vibration and shock as a circumstance that may happen simultaneously or consecutively, the results of the two evaluation tests are discussed in the same section. However, during the launch environment evaluation test, the two groups have been tested separately under vibration and shock. During the launch ground test's result evaluation, the criteria used during the space evaluation for the vacuum and the thermal vacuum test have been used [15]. The criteria (\#3 in Table 8) have been adopted, which are a combination of the two following criteria for the change in values after each environmental test: Such as some projects at NASA used the first criteria (\#1 in Table VIII), others used the second criteria (\#2 in Table VIII) for the qualification test for the COTS battery.
TABLE VIII

PASS/FAIL CRITERIA FOR THE LAUNCH ENVIRONMENT TEST

\begin{tabular}{ccccc}
\hline \hline Criteria & OCV & IR & Mass & Capacity \\
\hline$\# 1[25]$ & $<0.1 \%$ & $<0.1 \%$ & 0.1 to $1 \%$ & $<5 \%$ \\
$\# 2[26]$ & $<0.5 \%$ & $/$ & $<0.5 \%$ & $<3 \%$ \\
$\# 3$ & 0.1 to $0.5 \%$ & $<0.1 \%$ & 0.1 to $0.5 \%$ & 3 to $5 \%$ \\
\hline \hline
\end{tabular}

\section{IV.1. Output Test's Conditions}

For each group, Fig. 10 shows the reel spectrum for the applied shock during the test, following the same test condition in Table III. The pickup sensors show that the acceleration during the test has exceeded the upper limit, because of the difficulty of tuning, while it is still higher than the lower limit which is more important for the credibility of the test. However, we could say that the batteries were exposed to an accepted shock level test even if the upper limit was exceeded. During the vibration test for the sine burst, the pickup sensors' records for $\mathrm{CH} 2, \mathrm{CH} 6$, and $\mathrm{CH} 7$; could reach the required limit at $7.5 \mathrm{G}$ with more than 10 cycles (typically only 3 to 5 are required), as represented in Fig. 10. $\mathrm{CH} 2$, $\mathrm{CH} 6$, and $\mathrm{CH} 7$ are respectively the records for the axes that have been exposed to the same sine burst excitation's direction during the second configuration. For the sinewave, Fig. 12 shows the real condition during the test where all the solid-state-ceramic batteries' jigs have been exposed during the low frequencies from 5 to $100 \mathrm{~Hz}$.

Finally, with the high frequencies, during the random vibration, Fig. 13 shows the real test spectrum generated during the test, following the inputs parameter required in Table VI, in which the batteries have been exposed to the random vibration between 20 and $2000 \mathrm{~Hz}$ within 2 minutes.

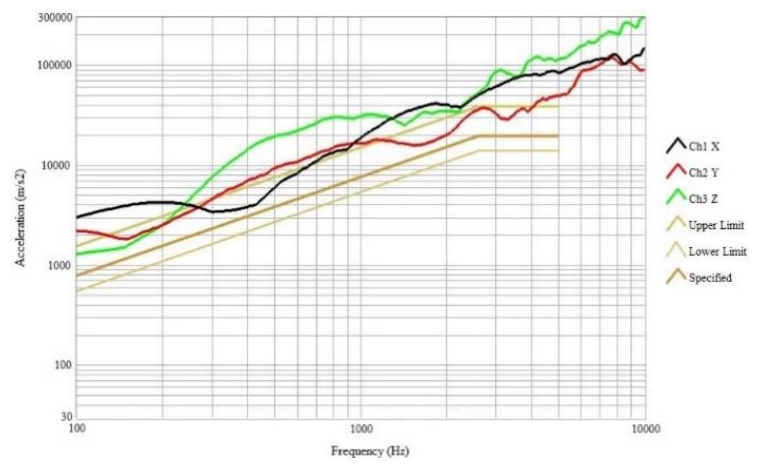

Fig. 10. Shock test pickup sensors' outputs spectrum

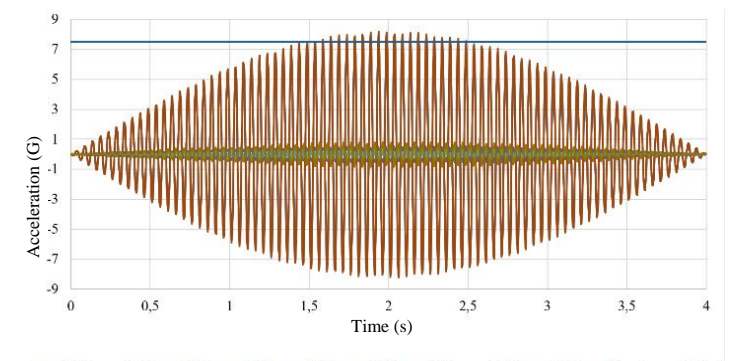

Fig. 11. Sine burst test pickup sensors' outputs, Jig 1 (CH:1,2,3), Jig 2 $(\mathrm{CH}: 4,5,6)$, and Jig $3(\mathrm{CH}: 7,8,9)$ 


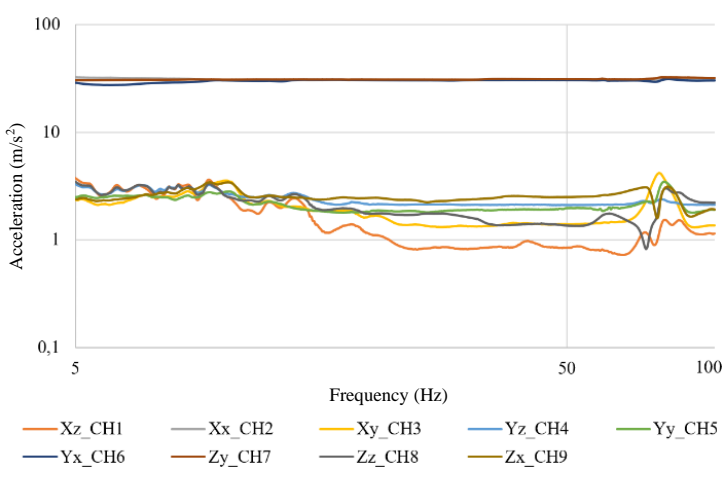

Fig. 12. Sinewave test pickup sensors' outputs recorded for the solidstate-ceramic batteries following the inputs' condition

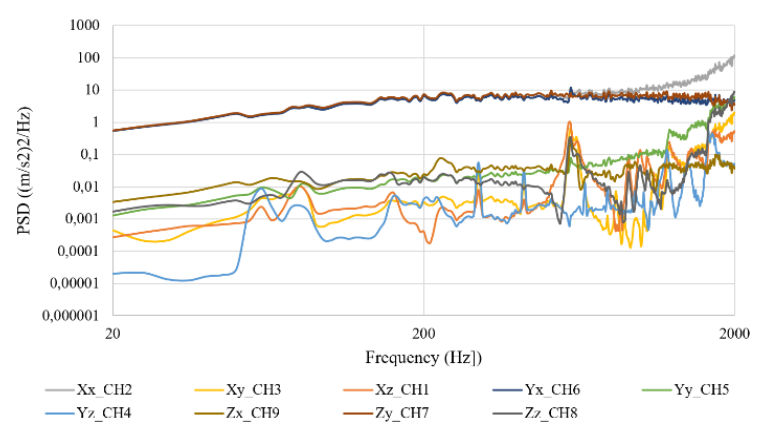

Fig. 13. Random test pickup sensors' outputs for the three jigs during the first configuration

\section{IV.2. Visual Inspection, Weight, and Open-Circuit Voltage Measurement}

At the end of the test with the non-functional check, no physical damage has been observed related to the fatigue, none of the batteries have shown a change in dimensions or weight, Table IX summarizes the weight measurement before and after all the launch environment test. Otherwise, the change of value for the OCV measurements shows a variation exceeding the criteria's limits for some batteries (LCB02) with $0.2 \%$ excess as shown in Table X. After comparing the measurements between after the shock; which the results have shown no significant variation in value at the order of $10^{-3}$; and after the vibration, it has been concluded that the change of the value has been induced by the vibration and not the shock. However, the exceeding could not be used for judgment until the function test has been done which will give the more significant interpretation.

TABLE IX

WEIGHT MEASUREMENT BEFORE AND AFTER TEST

\begin{tabular}{ccccccc}
\multicolumn{6}{c}{ WEIGHT MEASUREMENT BEFORE AND AFTER TEST } \\
\hline \hline LCB & $01 \# 1$ & $01 \# 2$ & $01 \# 3$ & $02 \# 1$ & $02 \# 2$ & $02 \# 3$ \\
\hline Before $(\mathrm{g})$ & 58,32 & 58,38 & 58,18 & 45,44 & 45,56 & 45,46 \\
After $(\mathrm{g})$ & 58,33 & 58,37 & 58,17 & 45,43 & 45,56 & 45,45 \\
Difference $(\%)$ & 0,02 & 0,02 & 0,02 & 0,02 & 0,00 & 0,02 \\
\hline \hline
\end{tabular}

TABLE $X$

OCV MEASUREMENT BEFORE AND AFTER TEST

\begin{tabular}{ccccccc}
\hline LCB & $01 \# 1$ & $01 \# 2$ & $01 \# 3$ & $02 \# 1$ & $02 \# 2$ & $02 \# 3$ \\
\hline Before (V) & 4,21 & 4,21 & 4,23 & 4,28 & 4,28 & 4,28 \\
After (V) & 4,19 & 4,21 & 4,21 & 4,25 & 4,25 & 4,25 \\
Difference (\%) & 0,48 & 0,00 & 0,47 & $\mathbf{0 , 7 0}$ & $\mathbf{0 , 7 0}$ & $\mathbf{0 , 7 0}$ \\
\hline
\end{tabular}

\section{IV.3. Functional Test Results}

After the batteries have been exposed to the shock and vibration test, several charges and discharges cycles have been performed showing that batteries have been able to operate several cycles in normal conditions which means that the hostile environment did not affect the charge mode of batteries.

As shown in Fig. 14 and Fig. 15, the constant-current constant-voltage (CC-CV) mode has been perfectly followed, starting charging with a Constant-Current (CC) at $\sim 1.3 \mathrm{~A}$ and a voltage at $\sim 3.4 \mathrm{~V}$ for LCB01, and $\sim 0.8 \mathrm{~A}$ and $\sim 3.3 \mathrm{~V}$ for LCB02, the constant-current has been switched to the Constant-Voltage $(\mathrm{CV})$ at $\sim 4.1$ to $4.2 \mathrm{~V}$, then the charge stopped when the batteries have been fully charged. However, for the discharge mode and the capacity evaluation, Fig. 16 and Fig. 17 represent the result of the discharge capacity after the shock only, and after all the test compared to the before test discharge capacity.

All batteries have been discharged at the required discharge current, $\sim 0.92 \mathrm{~A}$ for LCB01, and $\sim 0.72 \mathrm{~A}$ for LCB02, with the same discharge rate $0.5 \mathrm{C}$. It has been noticed that the LCB01 batteries show a decrease in capacity so far not exceeding the limit of $3 \%$ after the shock and vibration only, and between $3 \%$ to $5 \%$ after all the test. While the only exception is for one LCB02 battery which has shown a decrease of more than $5 \%$ after all the test, it may due that the battery was already in bad condition or manufacturing defect, the others LCB02 show no significant loose in capacity, less than $3 \%$ after the shock, between $3 \%$ to $5 \%$ after the vibration and all the test.

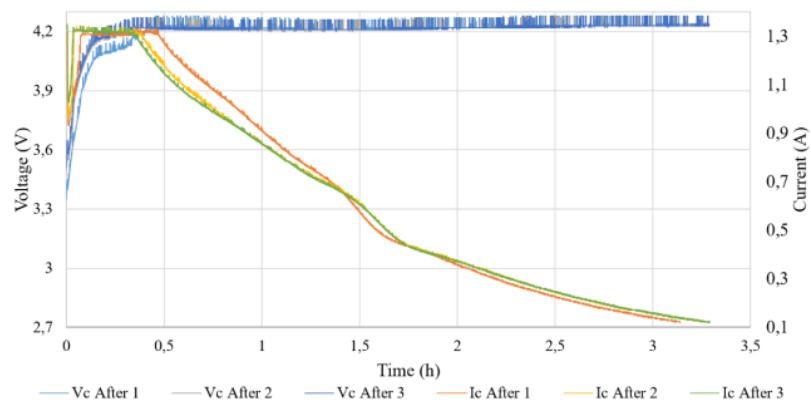

Fig. 14. Charge cycles for LCB01 $1950 \mathrm{mAh}$, group's samples for one jig after the launch evaluation test

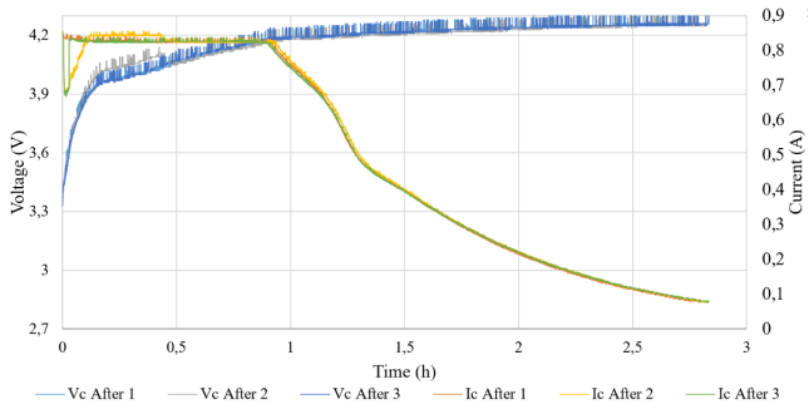

Fig. 15. Charge cycles for LCB02 $1450 \mathrm{mAh}$, group's samples for one jig after the launch evaluation test 


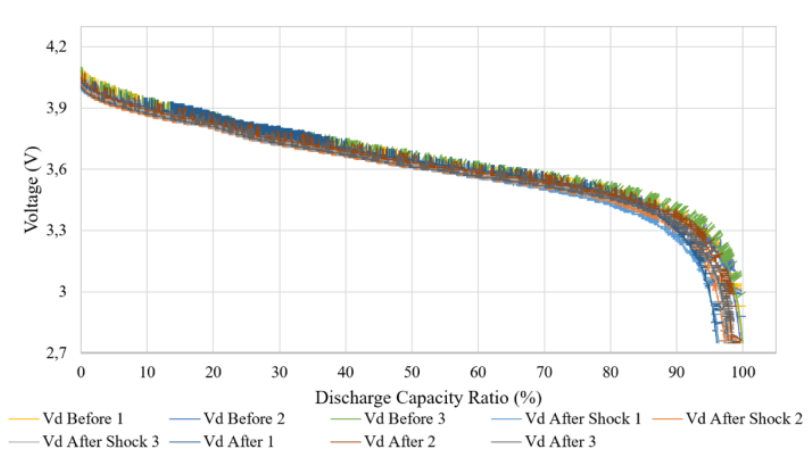

Fig. 16. Discharge voltage vs discharge capacity ratio for LCB01 1950 mAh. Group's samples for one jig: before, after the shock tests, and after the 3 axis vibration tests

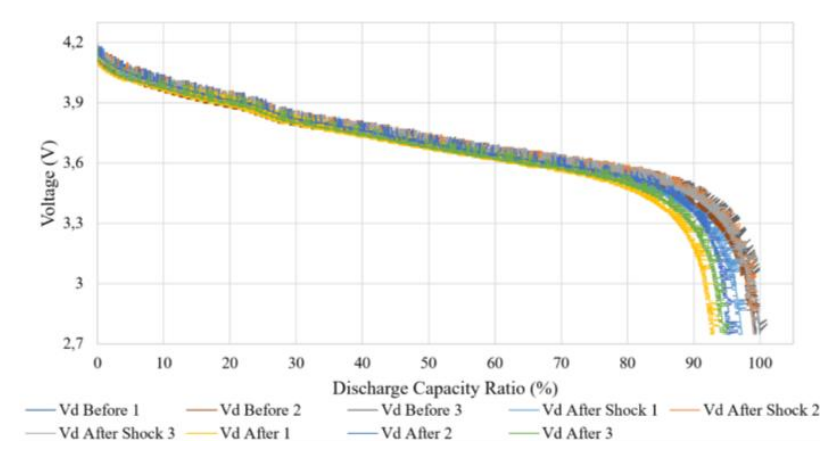

Fig. 17. Discharge voltage vs discharge capacity ratio for LCB02 1450 $\mathrm{mAh}$. Group's samples for one jig: before, after the shock tests, and after the 3 axis vibration tests

\section{Conclusion}

So far, the results from the evaluation within the launch environment conditions for the solid-stateceramic batteries show that all batteries have not been affected by the high vibration and the high shock level.

The batteries could withstand the launch environment successfully; it can be noticed on the comparison between the capacity before and after the test that the batteries do not show any significant degradation: $83 \%$ of the solid-state-ceramic batteries tested could be able to keep their capacity with $95 \%$, which means that all LCB01 and two LCB02 have passed the launch environment evaluation, so far within the limits. Additionally, they have not shown any physical degradation.

The paper also summarizes the main steps for the battery's ground testing under the launch environment and some criteria which may be used for evaluation after the environment test.

After the space and the launch environment ground evaluation test have been done successfully, the next step is to design a mission board for orbit demonstration of the solid-state-ceramic battery on a real application onboard a low earth orbit small re-entry satellite, in which the battery will be able to be tested at the real conditions during more than one year in orbit, and then recovered after re-entry for further analysis.

\section{Acknowledgments}

The authors want to acknowledge the Ministry of Education, Culture, Sports, Science, and Technology of Japan (MEXT). Finally, TOA Electric Industrial and ProLogium Company.

\section{References}

[1] Li, X., Koseki, H., Thermal Analysis on Lithium Primary Batteries, (2014) International Journal on Energy Conversion (IRECON), 2 (4), pp. 133-136.

[2] Dongxu Ouyang, Mingyi Chen, Jian Wang, Que Huang, Jingwen Weng, Zhi Wang, Jian Wang, A Review on the Thermal Hazards of the Lithium-Ion Battery and the Corresponding Countermeasures, Journal of Applied Sciences (MDPI), vol. 9, no. 12, pp. $2483,2019$. doi: https://doi.org/10.3390/app9122483

[3] B. Mckissock, P. Loyselle, E. Vogel, Guidelines on Lithium-ion Battery Use in Space Applications, NASA Center for AeroSpace Information, May 2009.

https://ntrs.nasa.gov/archive/nasa/casi.ntrs.nasa.gov/20090023862 .pdf

[4] L. Zhang, Z. Ning, H. Peng, Z. Mu, \& C. Sun, Effects of vibration on the electrical performance of Lithium-ion cells based on mathematical statistics. Journal of Applied Sciences (MDPI), vol. 7, no. 8, pp. 802, 2017. doi: https://doi.org/10.3390/app7080802

[5] M.J. Brand, S.F. Schuster, T. Bach, E. Fleder, M. Stelz, S. Gläser, J. Müller, G. Sextl, A. Jossen, Effects of vibrations and shocks on lithium-ion cells, Journal of Power Sources (Elsevier), vol. 288, pp. 62-69, 2015. https://doi.org/10.1016/j.jpowsour.2015.04.107

[6] J.M. Hooper, J. Marco, G.H. Chouchelamane, J.S. Chevalier, D. Williams, Multi-axis vibration durability testing of lithium-ion 18650 NCA cylindrical cells, Journal of Energy Storage (Elsevier), vol 15, pp. 103-123, 2018. doi: https://doi.org/10.1016/j.est.2017.11.006

[7] J.M. Hooper, J. Marco, G.H. Chouchelamane, C. Lyness, Vibration durability testing of nickel manganese cobalt oxide (NMC) lithium-ion 18,650 battery cells, Journal of Energies (MDPI), vol 9, n.1, pp. 52, 2016. doi: https://doi.org/10.3390/en9010052

[8] Zhang L, Ning Z, Peng H, Mu Z, \& Sun C, Effects of vibration on the electrical performance of Lithium-ion cells based on mathematical statistics. Journal of Applied Sciences (MDPI), vol 7, n.8, pp. 802, 2017. doi: https://doi.org/10.3390/app7080802

[9] G. Kjell, J.F. Lang, Comparing different vibration tests proposed for li-ion batteries with vibration measurement in an electric vehicle, 2014 IEEE Conference: Electric Vehicle Symposium and Exhibition (EVS27), pp. 1-11, 2014. doi: https://doi.org/10.1109/EVS.2013.6914869

[10] K-H. Park, \& K-H. Yi, Space Qualification of Small Satellite Liion Battery System for the Secured Reliability. Journal of the Korean Society for Aeronautical \& Space Sciences, vol. 42, n.4, pp. 351-359, 2014. doi: https://doi.org/10.5139/jksas.2014.42.4.351

[11] S. Remy, S. Lawson, S. Lefeuvre, E. Mosset, \& M. Nestoridi, Qualification and Life Testing of Li-Ion Ves16 Batteries. E3S Web of Conferences, 16(1), 17009, 2017.

doi: https://doi.org/10.1051/e3sconf/20171617009

[12] J. Kim, P.Y. Lee, C.O. Youn, W. Na, M. Jang, Environmental tests and evaluations of variable 18650 cylindrical Li-Ion cells for space cell's qualification establishment, 2017 IEEE Energy Conversion Congress and Exposition (ECCE), pp. 1010-1015, 2017. doi: https://doi.org/10.1109/ECCE.2017.8095897

[13] Z. Cameron, C.S. Kulkarni, A.G. Luna, K. Goebel, S. Poll, A battery certification testbed for small satellite missions, 2015 IEEE Auto Test Conference, 2015-December, pp. 162-168, 2015. doi: https://doi.org/10.1109/AUTEST.2015.7356483 
[14] Monteiro J. P, Rocha R. M, Silva A, Afonso R, \& Ramos N, Integration and verification approach of ISTSat-1 CubeSat. Journal of Aerospace (MDPI), vol 6, n. 12, 2019. doi: https://doi.org/10.3390/aerospace6120131

[15] Limam, L., Hatanaka, K., Gonzalez-Llorente, J., Chihiro, M., Chikashi, T., Okuyama, K., Space Environment Evaluation Test of Solid-State-Ceramic Battery Advanced Energy Storage Under Vacuum and Thermal Vacuum, (2020) International Review of Aerospace Engineering (IREASE), 13 (2), pp. 68-79. doi: https://doi.org/10.15866/irease.v13i2.18582

[16] Placke T, Kloepsch R, Dühnen S, \& Winter M. Lithium ion, lithium metal, and alternative rechargeable battery technologies: the odyssey for high energy density. Journal of Solid State Electrochemistry, 21(7), 1939-1964, 2017. doi: https://doi.org/10.1007/s10008-017-3610-7

[17] Kim J. G, Son B, Mukherjee S, Schuppert N, Bates A, Kwon O, Choi M. J, Chung H. Y, \& Park S, A review of lithium and nonlithium based solid state batteries. Journal of Power Sources, 282, 299-322, 2015. doi: https://doi.org/10.1016/j.jpowsour.2015.02.054

[18] S. Asada, N. Abe, SSC03-II-4 Launching Small Satellites on the H-IIA Rocket, pp. 1-6, Small Satellite Conference, Utah State University, Logan, UT, article ID SSC03-II-4, 2003.

[19] Mitsubishi Heavy Industries Ltd, H2A Rocket User's Manual Ver.4.0, February 2015.

[20] J. Gonzalez-Llorente, A. A. Lidtke, K. Hatanaka, R. Kawauchi, and K.-I. Okuyama, Solar Module Integrated Converters as Power Generator in Small Spacecrafts: Design and Verification Approach, Journal of Aerospace (MDPI), vol. 6, no. 5, pp. 61, 2019 doi: https://doi.org/10.3390/aerospace6050061

[21] I. Fajardo et al., Design, Implementation, and Operation of a Small Satellite Mission To Explore the Space Weather Effects in Leo, Journal of Aerospace (MDPI), vol. 6, n. 10, pp. 108, 2019. doi: https://doi.org/10.3390/aerospace6100108

[22] Bendoukha, S., Tapia, I., Okuyama, K., Cho, M., An Experimental and Theoretical Study of Spatial Langmuir Probe Plasma System for a Small Lean Satellite Called Ten-Koh, (2019) International Review of Aerospace Engineering (IREASE), 12 (3), pp. 131-140. doi: https://doi.org/10.15866/irease.v12i3.15927

[23] H. Masui, T. Hatamura, M. Cho, Testing of Micro/Nano Satellites and Their On-orbit Performance, 27th Annual AIAA/USU Conference of Small Satellite, Logan, UT, paper ID: SSC13-WK8, pp. 1-7, 2013.

[24] Ryunosuke Shibaki, Development and Verification of Power System for High Voltage Technology Demonstration Satellite "Horyu 2", Master's Thesis, The Kyushu Institute of Technology, Kitakyushu, Japan, 2011. https://kitsat.net/documents/shibagaki_part5.pdf

[25] G. Pistoia, Lithium-Ion Batteries: Advances and Applications, First edit, Elsevier B.V, pp. 664, 2014. doi: https://doi.org/10.1016/C2011-0-09658-8

[26] Samuel Russell, David Delafuente, Eric Darcy, Karla Bradley, Edgar O. Castro, and Lauri Hansen, NASA's Technical Standards. Crewed Space Vehicle Battery Safety Requirements, Houston, Texas, pp. 124, 2017. https://standards.nasa.gov/standard/jsc/jsc-20793

\section{Authors' information}

${ }^{1}$ Kyushu Institute of Technology, Kit-Okuyama-Lab, Department of Applied Science for Integrated Systems Engineering, 1-1 Sensui, Tobata, Kitakyushu, Fukuoka 804-8550, Japan.

${ }^{2}$ Universidad Sergio Arboleda Escuela de Ciencias e Ingenieria, Call 74 No.14-14, Bogota, Colombia.

${ }^{3}$ Nihon University College of Science \& Technology, Department of Space Systems Engineering, 7 Chome-24-1 Narashinodai, Funabashi, Chiba 274-0063.

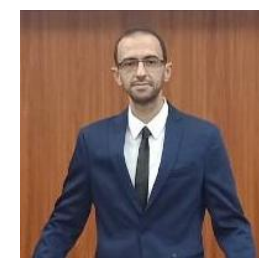

Lakhdar Limam graduated from the natura and life science, he received his baccalaureate in 2006, he got an engineering degree in instrumentation on hand veins biometric acquisition system the Institute of Industrial Safety and Maintenance (IMSI) of Oran, Algeria in 2011. He followed training in space engineering at the China Academy of Space Technology (CAST) in Beijing, China, from 2016 to 2017. He received his master's degree in automatic on attitude simulation of a satellite in geostationary orbit from the University of Science and Technology of Oran (USTO), Algeria, in 2017. He received the United Nations/Japan Long-term Fellowship to participated in the Space Engineering International Course in the Department of Applied Science for Integrated Systems Engineering in Kyutech, Japan, as part of the Postgraduate Study on Nanosatellite Technology in collaboration with United Nations Office for Outer Space Affairs (UNOOSA) in 2018. He is the team leader manager of the future re-entry satellite development for space environment measurements, research on carbon Fiber/PEEK, ablator material, and demonstration in orbit of solid-state battery. His research's interest is related to satellite system engineering and improvement of small satellites with the application of new technology in space, he is working on electrical power system for small satellites and application of solid-state battery in space. Mr. Limam joined the Algerian Space Agency (ASAL) in 2014, and worked at the Satellite Development Center in Oran, as metrology and instrumentation engineer from then an electrical engineer at the department of assembly, integration and test. He participated in the first Algerian telecommunication satellite development ALCOMSAT-1 launched in 2017, following training as a satellite engineer and ground station control for a geostationary satellite.

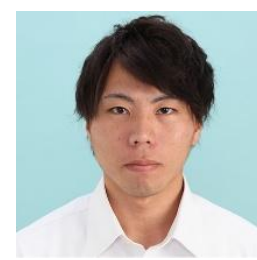

Ken Hatanaka received his undergraduate degree in integrated system engineering from the Kyushu Institute of Technology at Kitakyushu, Japan in 2018. He was involved in Ten-Koh satellite launched in 2018, a small satellite project for space weather effects exploration in low earth orbit, he was in charge of electrical power system design with the electrical team for designing a solar module integrated converter as power generator and demonstration of supercapacitors in low earth orbit. Mr. Ken is a master student in the integrated system at the Department of Applied Science for Integrated Systems Engineering at the Kyushu Institute of Technology at Kitakyushu, Japan. His research's interest is in the electrical power system for small satellites, and solid-state batteries.

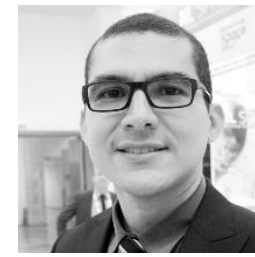

Jesus Gonzalez-Llorente received his undergraduate degree in electronics engineering from the Universidad Nacional de Colombia at Manizales in 2003, his M.S. degree in electrical engineering from the University of Puerto Rico | at Mayaguez in 2009, and his Ph.D.degree in Engineering from the Kyushu Institute of Technology at Kitakyushu, Japan in 2019. He was a researcher in the National Astronomy and Ionosphere Center Arecibo Observatory under Cornell University operation during 2010. $\mathrm{He}$ also has been a research professor at Universidad Sergio Arboleda in Bogota, Colombia, an adjunct professor at the University of Puerto Rico at Mayaguez and a visiting scholar at the University of Arkansas in Fayetteville, USA. He has published over 30 refereed papers in recognized conferences and journals. His research activities include modeling and control of low power dc-dc converters, solar photovoltaic systems, design of electrical power systems for small satellites, and systems engineering. Dr. Gonzalez-Llorente is an IEEE member, and he has served as a reviewer and technical committee member of recognized conferences. He received the Emerging Space Leader Grant from the International Astronautical Federation in 2015. He also received the United Nations/Japan Long-term Fellowship from 20162019 to participated in the Space Engineering International Course in the Department of Applied Science for Integrated Systems Engineering in Kyutech, Japan, as part of the Post-graduate Study on Nanosatellite Technology in collaboration with United Nations Office for Outer Space Affairs (UNOOSA) 


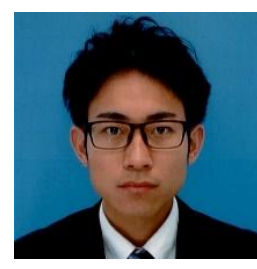

Masayuki Miyazaki received his undergraduate degree in integrated system engineering from the Kyushu Institute of Technology at Kitakyushu, Japan in 2018. He participated in the development of Ten-Koh, a low-Earth orbit environment observation satellite launched in 2018, and was responsible for structural design, structural analysis, and testing of each structure. Mr. Miyazaki is a master student in the integrated system at the Department of Applied Science for Integrated Systems Engineering at the Kyushu Institute of Technology at Kitakyushu, Japan. His research topics are the development of the structure of quasi-spherical small satellites and research on a simple method for deriving natural frequencies.

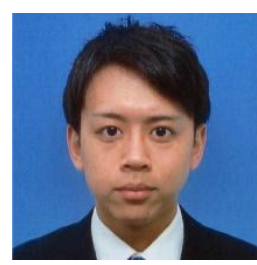

Takeya Chikashi is a Bachelor student in the Department of Applied Science for Integrated Systems Engineering in the Kyushu Institute of Technology at Kitakyushu, Japan. $\mathrm{He}$ is involved in the future re-entry satellite development for space environment measurements, research on carbon Fiber/PEEK, ablator material, and demonstration in orbit of solid-state battery. His research's interest is in the evaluation of solidstate batteries under vibration and shock tests.

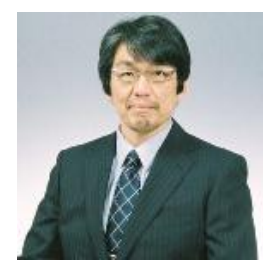

Kei-Ichi Okuyama received a B.Sc degree from Faculty of Engineering, Takai University in 1986. In 1988, he obtained an M.Sc degree from Division of Engineering of Muroran Institute of Technology, Japan, and respectively his Ph.D. grade in 2004 at Osaka University, Japan. $\mathrm{He}$ was a researcher at Kawasaki Heavy Industry Ltd, Japan from 1994 to 2006, and he started working as an associate professor in Tsuyama National College of Technology, Japan from 2006 to 2009 and continue working as the position at Aichi University of Technology, Japan until 2010, he was nominated as a full professor at Aichi University from 2010 to 2012. Since 2012, Dr. Kei-Ichi joined The Kyushu Institute of Technology, Kitakyushu, Japan at the Department of Applied Science for Integrated System Engineering. He has published several refereed papers in recognized conferences and journals. His main research field focuses on aerospace engineering, spacecraft reentry, satellite structure and material, and ablative material. 